ORIGINAL ARTICLE

\title{
Impact of hypertension on coronary artery spasm as assessed with intracoronary acetylcholine provocation test
}

\author{
K-Y Chen ${ }^{1}$, S-W Rha ${ }^{1}$, Y-J Li ${ }^{1}$, KL Poddar ${ }^{1}$, Z Jin ${ }^{1}$, Y Minami ${ }^{2}$, S Saito ${ }^{2}$, JH Park ${ }^{1}$, JO Na ${ }^{1}$, \\ CU Choi ${ }^{1}$, HE Lim ${ }^{1}$, JW Kim ${ }^{1}$, EJ Kim ${ }^{1}$, CG Park ${ }^{1}$, HS Seo ${ }^{1}$ and DJ Oh ${ }^{1}$ \\ ${ }^{1}$ Department of Internal Medicine, Cardiovascular Center, Korea University Guro Hospital, Seoul, Korea and \\ ${ }^{2}$ Department of Internal Medicine, Cardiovascular Center, Shonan Kamakura General Hospital, Kamakura, \\ Japan
}

Both hypertension and coronary artery spasm (CAS) are associated with endothelial dysfunction. Thus, a higher incidence of CAS is expected in hypertensive patients. We evaluated the impact of hypertension on CAS with intracoronary acetylcholine (ACh) provocation test. A total of 986 patients (685 hypertensive patients vs 301 normotensive patients) who underwent coronary angiography with ACh provocation test were enrolled. ACh was injected into the left coronary artery in incremental doses of 20,50 and $100 \mu \mathrm{g} \mathrm{min}^{-1}$. Significant CAS was defined as a transient $>70 \%$ luminal narrowing with concurrent chest pain and/or ST-segment changes. Although the incidences of significant $\mathrm{ACh}$-induced CAS were similar between hypertensive and normotensive patients (35.8 vs $39.2 \%, P=0.303)$, multivariate logistic analysis showed that hypertension was negatively associated with $\mathrm{ACh}$-induced CAS (odds ratio: 0.70 ,
95\% confidence interval: $0.51-0.94, P=0.020)$. The angiographic characteristics of ACh-induced CAS were similar between these two groups. Subgroup analysis regarding the impact of the status of blood pressure control on CAS showed that hypertensive patients with controlled blood pressure had a significantly higher incidence of CAS than those with uncontrolled blood pressure (45.2 vs $27.9 \%$, $P<0.001$ ), and that uncontrolled blood pressure was negatively associated with ACh-induced CAS (odds ratio: 0.56, $95 \%$ confidence interval: $0.40-0.79, P=0.001)$. In conclusion, despite the expected endothelial dysfunction, hypertension and uncontrolled blood pressure are negatively associated with CAS, suggesting that the mechanisms and risk factors of CAS may be significantly different from those of coronary artery disease.

Journal of Human Hypertension (2010) 24, 77-85; doi:10.1038/jhh.2009.40; published online 21 May 2009

Keywords: acetylcholine; coronary artery spasm; blood pressure control

\section{Introduction}

Hypertension represents one of the most common conditions associated with increased cardiovascular risk, including stroke, myocardial infarction and heart failure. ${ }^{1}$ Numerous experimental and clinical research data have shown that hypertension is associated with significant endothelial dysfunction, which may represent a major pathogenic link between hypertension and coronary artery disease. ${ }^{2,3}$

Coronary artery spasm (CAS) plays an important role in the pathogenesis of vasospatic angina and acute coronary syndrome. Some earlier studies have suggested that patients with CAS have a disturbance in the endothelial function of the coronary arteries. ${ }^{4-6}$ Thus, it is reasonable to

Correspondence: Dr S-W Rha, Cardiovascular Center, Korea University Guro Hospital, 80, Guro-dong, Guro-gu, Seoul 152-703, Korea.

E-mail: swrha617@yahoo.co.kr

Received 16 November 2008; revised 10 March 2009; accepted 18 March 2009; published online 21 May 2009 speculate that patients with hypertension may have a higher incidence of significant CAS. However, only several studies designed to analyse the multiple risk factors for CAS have briefly evaluated the impact of hypertension on CAS, and no earlier study to date has analysed the impact of the status of blood pressure control on CAS. ${ }^{7-9}$ Therefore, in this study, we evaluated the impact of hypertension and the status of blood pressure control on CAS with intracoronary acetylcholine (ACh) provocation test in a series of Korean hypertensive patients.

\section{Materials and methods}

\section{Study population}

The study flow chart was shown in Figure 1. A total of 986 patients, 685 patients with hypertension and 301 patients with normotension were enrolled into this study. The study protocol was approved by the institutional review board at Korea University, Guro Hospital (Seoul, Korea) and written informed consent was obtained from every patient before study entry. 


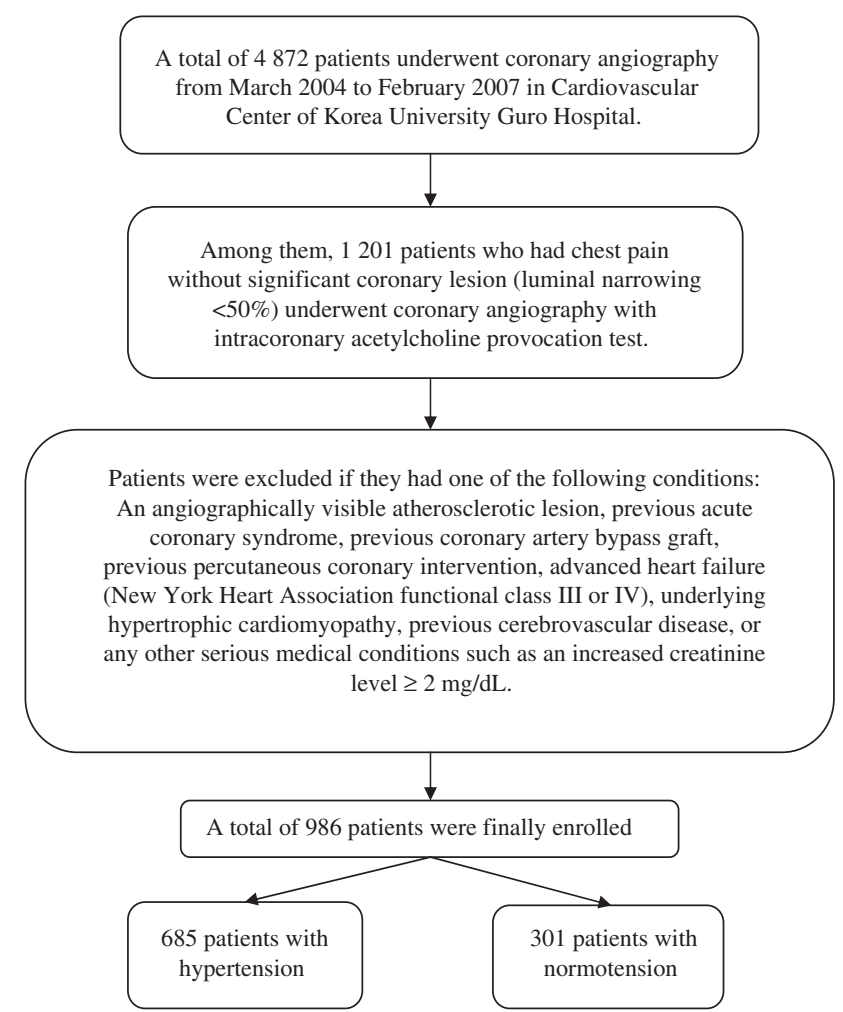

Figure 1 Study flow chart.

\section{Acetylcholine provocation test}

Coronary artery spasm was induced by intracoronary injection of ACh after diagnostic catheterization in the morning. The details of the method were reported earlier. ${ }^{10,11}$ In brief, nitrates, calcium channel blockers (CCBs), $\beta$-blockers, angiotensin-converting enzyme inhibitors, angiotensin II receptor blockers and other vasodilators or vasoconstrictors were withheld at least $72 \mathrm{~h}$ before coronary angiography. ACh was injected in incremental doses of 20 (A1), 50 (A2) and 100 (A3) $\mu$ g into the left coronary artery over a $1 \mathrm{~min}$ period with $5 \mathrm{~min}$ intervals to the maximum tolerated dose under continuous monitoring of electrocardiogram (ECG) and blood pressure. Angiography was repeated after each ACh dose. After that, an intracoronary infusion with $0.2 \mathrm{mg}$ nitroglycerin was given. Angiography was then performed $2 \mathrm{~min}$ later. If focal or diffuse significant vasoconstriction of coronary arteries was induced with any dose of ACh, the ACh infusion was stopped. End-systolic and end-diastolic images for each segment of the left coronary artery were chosen according to the corresponding points on the electrocardiographic trace (QRS onset or end of $\mathrm{T}$ wave) and analysed using the proper quantitative coronary angiographic system of the catheterization laboratory (BH-3000, Philips, Amsterdam, The Netherlands). The quantitative measuring variable was described as percent change from baseline on an angiogram. Two expert observers analysed the angiographic images at right anterior oblique cranial views and the evaluated QCA data were entered into the database. The percent diameter change was measured at the most severely narrowed site of the significantly spastic artery.

\section{Study definitions}

Brachial blood pressure was measured in triplicate in the right arm with a cuff and mercury sphygmomanometer after the patient rested in a seated position for $5 \mathrm{~min}$. The average of the last two measurements was used as brachial blood pressure. Pulse pressure was calculated as the difference between systolic and diastolic pressures. Hypertension was diagnosed according to the following criteria: (1) a history of diagnosed hypertension status and treatment with medications, diet and/or exercises; (2) systolic blood pressure $\geqslant 140 \mathrm{~mm} \mathrm{Hg}$ or diastolic blood pressure $\geqslant 90 \mathrm{~mm} \mathrm{Hg}$ on at least two occasions; (3) current use of antihypertensive pharmacological therapy to control hypertension. ${ }^{12}$ In this retrospective study, we reviewed all the hypertensive patients' in-hospital medical records about blood pressure before the temporal cessation of vasodilators; if the hypertensive patient's systolic blood pressure was $\geqslant 140 \mathrm{~mm} \mathrm{Hg}$ or diastolic blood pressure was $\geqslant 90 \mathrm{~mm} \mathrm{Hg}$ with the treatment of antihypertensive agents on calm occasions, he or she was identified as an uncontrolled blood pressure patient or else as a controlled blood pressure patient.

Hyperlipidaemia was defined as total cholesterol level $\geqslant 200 \mathrm{mg}$ per $100 \mathrm{ml}$ or current treatment with lipid-lowering drugs. Current cigarette smoking was defined as active smoking within the past 12 months. Diabetes was defined as fasting blood glucose $\geqslant 126 \mathrm{mg}$ per $100 \mathrm{ml}$, or the use of hypoglycaemic agents or insulin. Peripheral arterial disease (PAD) was defined as a claudication symptom with ankle brachial indexes $<0.90$, and/or a claudication symptom with any angiographic finding of significant lesion in the peripheral artery and/or symptomatic carotid or subclavian arterial disease documented by image studies.

During the ACh provocation test, significant CAS was defined as a $>70 \%$ decrease in the arterial luminal diameter with concurrent chest pain and/or ST-segment elevation or depression $\geqslant 1 \mathrm{~mm}$. Myocardial bridge was considered when the characteristic phasic compression of the coronary artery had a $>30 \%$ decrease in diameter on the angiogram after intracoronary nitroglycerin infusion. ${ }^{10,11}$

\section{Statistical analysis}

All the statistical analyses were performed using SPSS 11.0 (SPSS Inc., Chicago, IL, USA). For continuous variables, differences between groups were evaluated by unpaired $t$-test or Mann-Whitney rank-sum test. For discrete variables, differences were expressed as counts and percentages and analysed with $\chi^{2}$ (or Fisher's exact) test between 
groups as appropriate. Multivariate logistic regression analysis, which included baseline confounding factors, was used for assessing the independent impact of hypertension or the status of blood pressure control on ACh-induced significant CAS. A two-tailed $P$-value of $<0.05$ was considered to be statistically significant. Data were expressed as mean \pm standard deviation (s.d.).

\section{Results}

Impact of hypertension on coronary artery spasm The baseline clinical characteristics of normotensive and hypertensive patients are presented in Table 1. Patients with hypertension were older, had higher body mass index, systolic and diastolic blood pressure, pulse pressure and more frequently had diabetes, hyperlipidaemia and PAD, but less frequently had current smoking compared with those with normotension. Accordingly, hypertensive patients had higher rates of use aspirin, $\beta$-blockers, CCBs, angiotensin-converting enzyme inhibitors, angiotensin II receptor blockers and statins than did normotensive patients. Even though there was a trend towards a higher level of blood triglyceride in hypertensive patients, the blood levels of total cholesterol, low- and high-density lipoprotein cholesterol were similar between these two groups, reflecting the higher rate of use statins in hypertensive patients.

The characteristics of ACh provocation test were presented in Table 2. The reference diameters (mm)
$(1.84 \pm 0.49$ vs $1.81 \pm 0.47, P=0.504)$ and diameter narrowing (\%) $\quad(37.64 \pm 34.42$ vs $39.39 \pm 32.75$, $P=0.729$ ) of the coronary artery after ACh infusion were similar between patients with and without hypertension. Furthermore, the reference diameters of the coronary artery after nitroglycerin infusion were also similar between these two groups (mm) (2.58 \pm 0.54 vs $2.66 \pm 0.59, P=0.119)$. On account of the above results, the incidences of ACh-induced significant CAS did not differ significantly between patients with and without hypertension (35.8 vs $39.2 \%, P=0.303$ ). During ACh provocation test, the incidences of ST-segment change, chest pain, atrioventricular block and myocardial bridge were similar between these two groups.

In patients who had significant CAS, the characteristics of CAS were also similar between patients with and without hypertension, including the maximal tolerable doses of ACh, spasm types (focal vs diffuse) and spasm vessel number (Table 3).

As shown in Figure 2, the univariate logistic analysis in the general study population showed that ageing, male, hyperlipidaemia, current smoking, PAD and myocardial bridge were risk factors for ACh-induced significant CAS. However, multivariate logistic analysis showed that besides ageing, male, PAD and myocardial bridge, hypertension was an independent predictor, too. Hypertension was negatively associated with AChinduced CAS in multivariate logistic analysis (odds ratio: 0.70, 95\% confidence interval: 0.510.94, $P=0.020)$.

Table 1 Baseline clinical characteristics of the general study population

\begin{tabular}{|c|c|c|c|}
\hline Variables & $N T N(\mathrm{n}=301)$ & $H T N(\mathrm{n}=685)$ & $\mathrm{P}$-value \\
\hline Male, $n(\%)$ & $155(51.5)$ & $327(47.7)$ & 0.277 \\
\hline Age (years) & $50.45 \pm 12.20$ & $55.71 \pm 11.93$ & $<0.001$ \\
\hline Body mass index $\left(\mathrm{kg} \mathrm{m}^{-2}\right)$ & $23.38 \pm 3.53$ & $24.25 \pm 3.14$ & 0.002 \\
\hline Diabetes mellitus, $n(\%)$ & $20(6.6)$ & 86 (12.6) & 0.006 \\
\hline Hyperlipidemia, $n(\%)$ & $9(3.0)$ & $119(17.4)$ & $<0.001$ \\
\hline Current smoking, $n(\%)$ & $87(28.9)$ & $144(21.0)$ & 0.007 \\
\hline Family history of coronary artery disease, $n(\%)$ & $20(6.6)$ & $42(6.1)$ & 0.760 \\
\hline Peripheral arterial disease, $n(\%)$ & $3(1.0)$ & $78(11.4)$ & $<0.001$ \\
\hline Systolic blood pressure (mm Hg) & $119.91 \pm 11.02$ & $145.68 \pm 21.04$ & $<0.001$ \\
\hline Diastolic blood pressure (mm Hg) & $73.41 \pm 7.23$ & $87.47 \pm 11.65$ & $<0.001$ \\
\hline Pulse pressure $(\mathrm{mm} \mathrm{Hg})$ & $46.50 \pm 8.78$ & $58.20 \pm 15.71$ & $<0.001$ \\
\hline Total cholesterol (mg per $100 \mathrm{ml}$ ) & $172.04 \pm 38.30$ & $176.51 \pm 39.15$ & 0.109 \\
\hline Triglyceride (mg per $100 \mathrm{ml})$ & $121.86 \pm 79.37$ & $134.67 \pm 96.14$ & 0.064 \\
\hline Low-density lipoprotein cholesterol (mg per $100 \mathrm{ml}$ ) & $111.84 \pm 35.82$ & $114.76 \pm 57.03$ & 0.565 \\
\hline High-density lipoprotein cholesterol (mg per $100 \mathrm{ml}$ ) & $51.50 \pm 14.00$ & $52.40 \pm 17.96$ & 0.482 \\
\hline Aspirin, $n(\%)$ & $41(13.6)$ & $180(26.3)$ & $<0.001$ \\
\hline Cilostazol, $n(\%)$ & $8(2.7)$ & $13(1.9)$ & 0.447 \\
\hline$\beta$-Blockers, $n(\%)$ & $14(4.7)$ & $62(9.1)$ & 0.017 \\
\hline Calcium channel blockers, $n(\%)$ & $115(38.2)$ & $323(47.2)$ & 0.009 \\
\hline Angiotensin-converting enzyme inhibitors, $n(\%)$ & $5(1.7)$ & $32(4.7)$ & 0.022 \\
\hline Angiotensin II receptor blockers, $n(\%)$ & $11(3.7)$ & $94(13.7)$ & $<0.001$ \\
\hline Nitrates, $n(\%)$ & $90(29.9)$ & $174(25.4)$ & 0.142 \\
\hline Nicorandil, $n(\%)$ & $29(9.6)$ & $71(10.4)$ & 0.726 \\
\hline Statins, $n(\%)$ & $37(12.3)$ & $134(19.6)$ & 0.005 \\
\hline
\end{tabular}

Abbreviations: NTN, normotension; HTN, hypertension. 
Table 2 Characteristics of ACh provocation test in general study population

\begin{tabular}{|c|c|c|c|}
\hline Variables & $N T N(\mathrm{n}=301)$ & $H T N(\mathrm{n}=685)$ & P-value \\
\hline Reference diameter after NTG infusion (mm) & $2.66 \pm 0.59$ & $2.58 \pm 0.54$ & 0.119 \\
\hline Reference diameter after ACh infusion (mm) & $1.81 \pm 0.47$ & $1.84 \pm 0.49$ & 0.504 \\
\hline Diameter narrowing after ACh infusion (\%) & $39.39 \pm 32.75$ & $37.64 \pm 34.42$ & 0.729 \\
\hline Acetylcholine-induced significant CAS, n (\%) & $118(39.2)$ & $245(35.8)$ & 0.303 \\
\hline ST-segment change, n (\%) & $18(6.0)$ & $43(6.3)$ & 0.858 \\
\hline Chest pain, $n(\%)$ & $137(45.5)$ & $284(41.5)$ & 0.236 \\
\hline Atrioventricular block, $n(\%)$ & $73(24.3)$ & $161(23.5)$ & 0.799 \\
\hline Myocardial bridge, $n(\%)$ & $73(24.3)$ & $163(23.8)$ & 0.877 \\
\hline
\end{tabular}

Abbreviations: NTG, nitroglycerine; ACh, acetylcholine; CAS, coronary artery spasm.

Table 3 Characteristics of acetylcholine provocation test in patients with significant coronary artery spasm

\begin{tabular}{|c|c|c|c|}
\hline Variables, $n(\%)$ & $N T N(\mathrm{n}=118)$ & $H T N(\mathrm{n}=245)$ & $\mathrm{P}$-value \\
\hline \multicolumn{4}{|c|}{ Maximal tolerable dose of acetylcholine } \\
\hline A1 $\left(20 \mu \mathrm{g} \mathrm{min}^{-1}\right)$ & $11(9.3)$ & $18(7.3)$ & 0.516 \\
\hline A2 $\left(50 \mu \mathrm{g} \mathrm{min}^{-1}\right)$ & $63(53.4)$ & $140(57.1)$ & 0.500 \\
\hline A3 $\left(100 \mu \mathrm{g} \mathrm{min}^{-1}\right)$ & $44(37.3)$ & $87(35.5)$ & 0.741 \\
\hline \multicolumn{4}{|l|}{ Spasm types } \\
\hline Focal & $14(11.9)$ & $40(16.3)$ & 0.263 \\
\hline Diffuse & $104(88.1)$ & $205(83.7)$ & 0.263 \\
\hline \multicolumn{4}{|l|}{ Spasm vessel number } \\
\hline One vessel & $58(49.2)$ & $122(49.8)$ & 0.909 \\
\hline Multivessel & $60(50.8)$ & $123(50.2)$ & 0.909 \\
\hline
\end{tabular}

Variables
Myocardial bridge
Peripheral arterial disease
Family history of coronary
artery discase
Ciabetes mellitus smoking
Hypertipidemia

Figure 2 Multivariate logistic analysis of the predictors for acetylcholine-induced significant coronary artery spasm in the general study population. $\bullet$ : unadjusted odds ratio; $\mathbf{\square}$ : adjusted odds ratio.

Impact of the status of blood pressure control on coronary artery spasm in hypertensive patients The baseline clinical characteristics of hypertensive patients with and without controlled blood pressure were similar, except that hypertensive patients with controlled blood pressure more frequently had hyperlipidaemia and PAD, and had higher rates of use nitrates and CCBs but a lower rate of use 
Table 4 Baseline clinical characteristics of hypertensive patients with vs without controlled blood pressure

\begin{tabular}{|c|c|c|c|}
\hline Variables & Uncontrolled $(\mathrm{n}=373)$ & Controlled $(\mathrm{n}=312)$ & P-value \\
\hline Male, n (\%) & $177(47.5)$ & $150(48.1)$ & 0.871 \\
\hline Age (years) & $55.77 \pm 11.78$ & $55.64 \pm 12.13$ & 0.889 \\
\hline Body mass index $\left(\mathrm{kg} \mathrm{m}^{-2}\right)$ & $24.35 \pm 3.12$ & $24.14 \pm 3.24$ & 0.483 \\
\hline Diabetes mellitus, $n(\%)$ & $47(12.6)$ & $39(12.5)$ & 0.968 \\
\hline Hyperlipidemia, $n(\%)$ & $47(12.6)$ & $72(23.1)$ & $<0.001$ \\
\hline Current smoking, $n(\%)$ & $78(20.9)$ & $66(21.2)$ & 0.938 \\
\hline Family history of coronary artery disease, $n(\%)$ & $22(5.9)$ & $20(6.4)$ & 0.781 \\
\hline Peripheral arterial disease, $n(\%)$ & $21(5.6)$ & $57(18.3)$ & $<0.001$ \\
\hline Systolic blood pressure (mm Hg) & $159.98 \pm 15.92$ & $128.52 \pm 11.38$ & $<0.001$ \\
\hline Diastolic blood pressure (mm Hg) & $92.97 \pm 10.43$ & $80.89 \pm 9.40$ & $<0.001$ \\
\hline Pulse pressure (mm Hg) & $67.02 \pm 14.39$ & $47.64 \pm 9.49$ & $<0.001$ \\
\hline Total cholesterol (mg per $100 \mathrm{ml}$ ) & $178.21 \pm 40.72$ & $174.51 \pm 37.19$ & 0.246 \\
\hline Triglyceride (mg per $100 \mathrm{ml})$ & $130.37 \pm 84.54$ & $139.89 \pm 108.50$ & 0.258 \\
\hline Low-density lipoprotein cholesterol (mg per $100 \mathrm{ml}$ ) & $111.58 \pm 69.40$ & $115.67 \pm 32.27$ & 0.613 \\
\hline High-density lipoprotein cholesterol (mg per $100 \mathrm{ml}$ ) & $53.12 \pm 20.41$ & $51.52 \pm 14.43$ & 0.300 \\
\hline Aspirin, $n(\%)$ & $96(25.7)$ & $84(26.9)$ & 0.725 \\
\hline Cilostazol, $n(\%)$ & $7(1.9)$ & $6(1.9)$ & 0.965 \\
\hline$\beta$-Blockers, $n(\%)$ & $36(9.7)$ & $26(8.3)$ & 0.549 \\
\hline Calcium channel blockers, $n(\%)$ & $158(42.4)$ & $165(52.9)$ & 0.006 \\
\hline Angiotensin-converting enzyme inhibitors, $n(\%)$ & $17(4.6)$ & $15(4.8)$ & 0.877 \\
\hline Angiotensin II receptor blockers, $n(\%)$ & $62(16.2)$ & $32(10.3)$ & 0.016 \\
\hline Nitrates, $n(\%)$ & $81(21.7)$ & $93(29.8)$ & 0.015 \\
\hline Nicorandil, $n(\%)$ & $38(10.2)$ & $33(10.6)$ & 0.868 \\
\hline Statins, $n(\%)$ & $71(19.0)$ & $63(20.2)$ & 0.704 \\
\hline
\end{tabular}

Table 5 Characteristics of acetylcholine provocation test in hypertensive patients with vs without controlled blood pressure

\begin{tabular}{|c|c|c|c|}
\hline Variables & Uncontrolled $(\mathrm{n}=373)$ & Controlled $(\mathrm{n}=312)$ & $\mathrm{P}$-value \\
\hline Reference diameter after NTG infusion (mm) & $2.56 \pm 0.60$ & $2.59 \pm 0.55$ & 0.256 \\
\hline Reference diameter after ACh infusion (mm) & $1.87 \pm 0.41$ & $1.73 \pm 0.43$ & 0.314 \\
\hline Diameter narrowing after ACh infusion, (\%) & $33.51 \pm 34.87$ & $45.62 \pm 35.71$ & 0.243 \\
\hline Acetylcholine-induced significant CAS, $n(\%)$ & $104(27.9)$ & $141(45.2)$ & $<0.001$ \\
\hline ST-segment change, $n(\%)$ & $21(5.6)$ & $22(7.1)$ & 0.445 \\
\hline Chest pain, $n(\%)$ & $136(36.5)$ & $148(47.4)$ & 0.004 \\
\hline Atrioventricular block, $n(\%)$ & $93(24.9)$ & $76(24.4)$ & 0.862 \\
\hline Myocardial bridge, $n(\%)$ & $61(16.4)$ & $102(32.7)$ & 0.001 \\
\hline
\end{tabular}

angiotensin II receptor blockers than those with uncontrolled blood pressure (Table 4).

The characteristics of ACh provocation test showed that although the diameter narrowing after ACh infusion were similar between these two groups, hypertensive patients with controlled blood pressure had a significantly higher incidence of significant CAS ( 45.2 vs $27.9 \%, P<0.001$ ). More patients in the controlled blood pressure group had myocardial bridge and chest pain during the provocation test than did those in the uncontrolled blood pressure group (Table 5).

In the hypertensive patients who had significant CAS, the characteristics of CAS were also similar between patients with and without controlled blood pressure, including spasm types (focal vs diffuse) and spasm vessel number. However, there was a trend towards a higher rate of significant CAS at A2 dose in hypertensive patients with controlled blood pressure than in those without controlled blood pressure (61.7 vs $51.0 \%, P=0.093$ ) (Table 6).
The multivariate logistic analysis, including the aforementioned parameters, showed that uncontrolled blood pressure was negatively associated with ACh-induced significant CAS (odds ratio: 0.56, $95 \%$ confidence interval: $0.40-0.79, \quad P=0.001)$ (Figure 3).

\section{Discussion}

Numerous experimental and clinical research data have shown that hypertension is associated with significant endothelial dysfunction. ${ }^{2}$ Therefore, the association between hypertension and endothelial dysfunction has been well established. Some studies have suggested that CAS is also associated with endothelial dysfunction. ${ }^{4-6,13}$ Kugiyama et $a .^{5}$ reported that there was a deficiency in endothelial nitric oxide activity in spasm arteries, which was responsible for the supersensitive reaction of the coronary artery resulting in the vasoconstrictor 
Table 6 Characteristics of acetylcholine provocation test in hypertensive patients with significant coronary artery spasm

\begin{tabular}{|c|c|c|c|}
\hline Variables, n (\%) & Uncontrolled $(\mathrm{n}=104)$ & Controlled $(\mathrm{n}=141)$ & $\mathrm{P}$-value \\
\hline \multicolumn{4}{|c|}{ Maximal tolerable dose of acetylcholine } \\
\hline $\mathrm{A} 1\left(20 \mu \mathrm{g} \min ^{-1}\right)$ & $7(6.7)$ & $11(7.8)$ & 0.751 \\
\hline A2 $\left(50 \mu \mathrm{g} \mathrm{min}^{-1}\right)$ & $53(51.0)$ & $87(61.7)$ & 0.093 \\
\hline A3 $\left(100 \mu \mathrm{g} \mathrm{min}^{-1}\right)$ & $44(42.3)$ & $43(30.5)$ & 0.056 \\
\hline \multicolumn{4}{|l|}{ Spasm types } \\
\hline Focal & $19(18.3)$ & $21(14.9)$ & 0.480 \\
\hline Diffuse & $85(81.7)$ & $120(85.1)$ & 0.480 \\
\hline \multicolumn{4}{|l|}{ Spasm vessel number } \\
\hline One vessel & $52(50.0)$ & $70(49.6)$ & 0.956 \\
\hline Multivessel & $52(50.0)$ & $71(50.4)$ & 0.956 \\
\hline
\end{tabular}

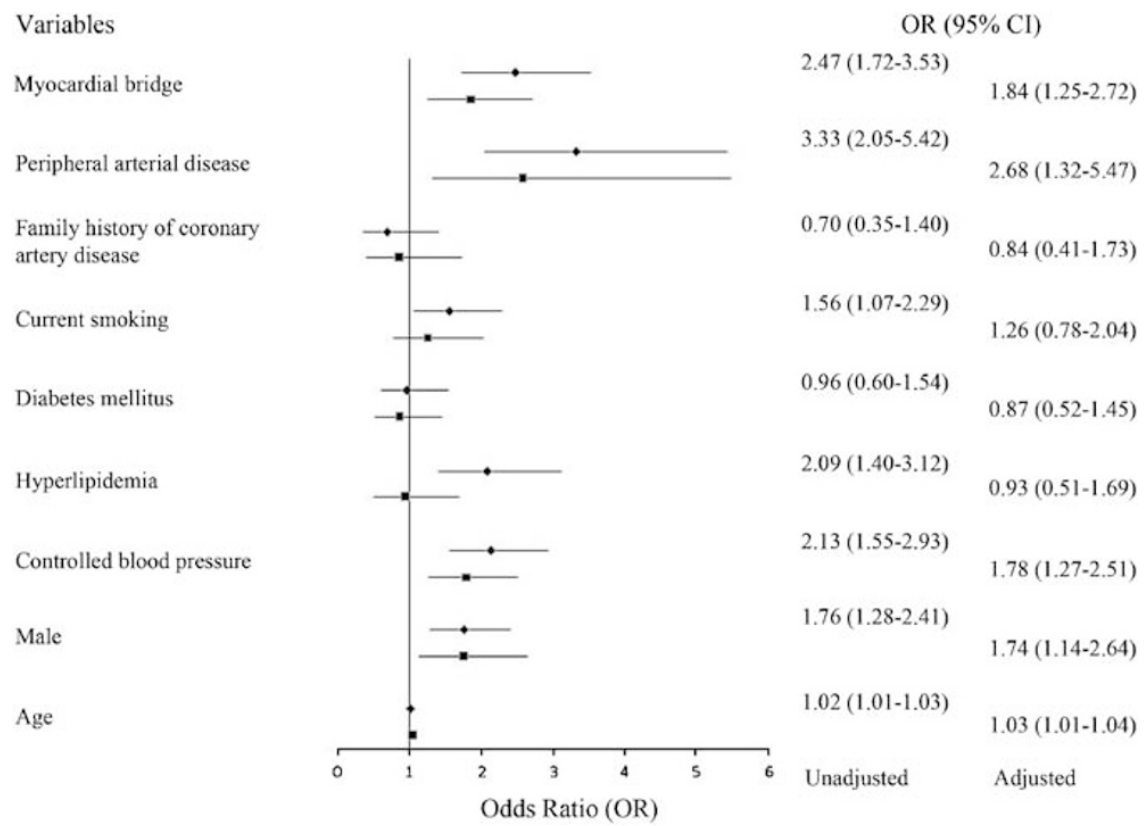

Figure 3 Multivariate logistic analysis of the predictors for acetylcholine-induced significant coronary artery spasm in hypertensive patients with vs without controlled blood pressure. $\bullet$ : unadjusted odds ratio; $\mathbf{a}$ : adjusted odds ratio.

effect of ACh in patients with CAS. Similarly, another study from Kugiyama et al. ${ }^{6}$ indicated that flow-dependent coronary dilation is impaired in spasm arteries, partly because of a deficiency in endothelial nitric oxide bioactivity. Recently, Yasue et $a l .{ }^{13}$ tested whether fluvastatin, a 3-hydroxy-3methylglutaryl coenzyme A reductase inhibitor (statin), could suppress coronary spasm based on the hypothesis that coronary spasm is associated with endothelial dysfunction. Their results showed that the addition of fluvastatin $30 \mathrm{mg}$ per day to the conventional CCB therapy for 6 months significantly reduced the number of patients with ACh-induced coronary spasm as compared with the conventional CCB therapy. Thus, in view of the above studies, ${ }^{4-6,13}$ it seems reasonable to conclude that CAS is associated with coronary endothelial dysfunction.
In this context, we tested the hypothesis that hypertensive patients might have a higher incidence of CAS than normotensive ones. In addition, some earlier studies ${ }^{14,15}$ have shown that medical treatment with controlled blood pressure can significantly reduce the incidence of cardiovascular events in hypertensive patients. However, the impact of the status of blood pressure control on the incidence of CAS has not been reported yet. Therefore, we also performed a subgroup analysis in hypertensive patients to test the hypothesis that the controlled blood pressure might be associated with a lower incidence of CAS because of the potentially improved endothelial function with medical treatment. However, in contrast to our initial expectation, hypertension and uncontrolled blood pressure were actually seen to be negatively associated with 
CAS as assessed by the intracoronary ACh provocation test. In this study, although hypertensive and normotensive patients had similar incidences of ACh-induced significant CAS and diameter narrowing after ACh infusion, multivariate logistic analysis showed that hypertension was negatively associated with ACh-induced significant CAS. The subgroup analysis performed in hypertensive patients showed that hypertensive patients with controlled blood pressure had a significantly higher incidence of CAS than those without, and that uncontrolled blood pressure was negatively associated with ACh-induced significant CAS. Therefore, collectively, our results suggested that lower blood pressure rather than higher blood pressure was positively associated with CAS. Patients with hypertension had a lower incidence of CAS compared with those with normotension, and this result seems to be driven mainly by the lower incidence of CAS in hypertensive patients with uncontrolled blood pressure.

The paradoxical impact of hypertension and the status of blood pressure control on CAS might be explained as follows. First, ACh has dual effects on the coronary artery tone depending on their intracoronary concentration. The normal response to ACh is vasodilation at small doses and vasoconstriction at higher doses when the direct vasoconstrictor effect of ACh overwhelms the stimulation of nitric oxide release. Thus, ACh-induced CAS in this study, we feel, does not necessarily signify endothelial dysfunction. ${ }^{16-18}$ Furthermore, the lack of vasodilation at small doses or mild degrees of vasoconstriction, which was not recognized as significant CAS, also reflects endothelial dysfunction. ${ }^{19,20}$ Thus, our results do not contradict the well-established concept that hypertension is closely associated with endothelial dysfunction.

Second, earlier studies have suggested that the pathogenesis of coronary vasospasm unassociated with significant coronary atherosclerosis differed from that of atherosclerosis because the major atherosclerotic risk factors, such as hyperlipidaemia and diabetes mellitus, were not significantly associated with CAS. ${ }^{8,21,22}$ Our results also supported this and showed that hyperlipidaemia and diabetes were not associated with CAS. Furthermore, beyond our initial expectation, we surprisingly found that hypertension and uncontrolled blood pressure were negatively associated with CAS. Therefore, more studies are needed to explore the mechanisms behind the association between hypertension and CAS.

Although the conventional risk factors for atherosclerosis such as hypertension, diabetes mellitus, hyperlipidaemia and smoking have been well established during the past several decades, less has been known about the risk factors for CAS. Several studies have analysed the risk factors for CAS, but the results seem varied..$^{8,21,22}$ Xiang et $a .^{8}$ reported the risk factors for ACh-induced CAS and showed that there was no significant association between CAS and sex, age, hypertension and positive treadmill test, but that smoking and hyperlipidaemia were independent risk factors for ACh-induced significant CAS. Kido et al. ${ }^{21}$ reported that smoking and family history in females were the most important risk factors for CAS, whereas other cardiovascular risk factors such as hypertension, hyperlipidaemia and diabetes did not show significant correlations with ACh-induced significant CAS. Sugiishi et $a .^{22}$ also showed that smoking was the major risk factor for CAS, but the lipid levels and diabetes mellitus were not independent risk factors for it.

Our present study showed that ageing, male, peripheral artery disease and myocardial bridge were independent risk factors for ACh-induced significant CAS. Our earlier study showed that myocardial bridge was significantly associated with CAS and was independent from the other cardiovascular risk factors. ${ }^{10,11}$ Thus, in this study, we co-analysed myocardial bridge with other cardiovascular risk factors. Interestingly, our results showed that hypertension and uncontrolled blood pressure were negatively associated with AChinduced significant CAS. These results are consistent with the results from Sugiishi et al. ${ }^{22}$ They also found that hypertension was negatively associated with CAS in a multivariate logistic analysis. However, in their study, they did not analyse the impact of the status of blood pressure control on the incidence of CAS.

\section{Study limitations}

This study has several obvious limitations. First, even though we minimized the confounding effects from the baseline biases with the multivariate logistic analysis, it is possible that some potential confounders might have crept in. However, we tested CAS in a relatively large study population, which is helpful in minimizing the confounding effects from the baseline biases. Second, angiographic evaluation of the changes in epicardial coronary diameter after the infusion of ACh as used in this study mainly reflects the functional status of coronary conduit vessels but not that for coronary microcirculation because hypertension affects not only the coronary conduit artery but also microcirculations. ${ }^{23,24}$ Thus, further studies measuring not only the coronary conduit artery spasm but also the coronary microvascular spasm in hypertensive patients are needed. Third, although we had carefully made the diagnosis of hypertension and thoroughly collected the information in detail about blood pressure for every patient, we did not collect the patient's blood pressure during the provocation test. However, some patients' blood pressure level might have obviously changed after they stopped their antihypertensive treatment. Fortunately, no patient in this study was found 
to have cardiovascular complications because of the provocation test and the temporal medication cessation.

What is known about this topic

- Numerous experimental and clinical research data have shown that hypertension is associated with significant endothelial dysfunction, which may represent a major pathogenic link between hypertension and coronary artery disease.

- Coronary artery spasm (CAS) plays an important role in the pathogenesis of vasospatic angina and acute coronary syndrome. Some earlier studies have suggested that patients with CAS have a disturbance in the endothelial function of the coronary arteries.

What this study adds

- Despite the expected endothelial dysfunction, hypertension and the uncontrolled blood pressure are negatively associated with coronary artery spasm. The relationship between hypertension and coronary artery spasm seems paradoxical.

- The mechanisms and risk factors of coronary artery spasm are significantly different from those of coronary artery disease.

\section{Conflict of interest}

The authors declare no conflict of interest.

\section{References}

1 Psaty BM, Lumley T, Furberg CD, Schellenbaum G, Pahor M, Alderman $\mathrm{MH}$ et al. Health outcomes associated with various antihypertensive therapies used as first-line agents: a network meta-analysis. JAMA 2003; 289: 2534-2544.

2 Davignon J, Ganz P. Role of endothelial dysfunction in atherosclerosis. Circulation 2004; 109: III27-III32.

3 Lavi S, Yang EH, Prasad A, Mathew V, Barsness GW, Rihal CS et al. The interaction between coronary endothelial dysfunction, local oxidative stress, and endogenous nitric oxide in humans. Hypertension 2008; 51: 127-133.

4 Kugiyama K, Murohara T, Yasue H, Kimura T, Sakaino $\mathrm{N}$, Ohgushi $\mathrm{M}$ et al. Increased constrictor response to acetylcholine of the isolated coronary arteries from patients with variant angina. Int J Cardiol 1995; 52: 223-233.

5 Kugiyama K, Yasue H, Okumura K, Ogawa H, Fujimoto $\mathrm{K}$, Nakao $\mathrm{K}$ et al. Nitric oxide activity is deficient in spasm arteries of patients with coronary spastic angina. Circulation 1996; 94: 266-271.

6 Kugiyama K, Ohgushi M, Motoyama T, Sugiyama S, Ogawa H, Yoshimura $\mathrm{M}$ et al. Nitric oxide-mediated flow-dependent dilation is impaired in coronary arteries in patients with coronary spastic angina. J Am Coll Cardiol 1997; 30: 920-926.

7 Takaoka K, Yoshimura M, Ogawa H, Kugiyama K, Nakayama M, Shimasaki Y et al. Comparison of the risk factors for coronary artery spasm with those for organic stenosis in a Japanese population: role of cigarette smoking. Int J Cardiol 2000; 72: 121-126.
8 Xiang D, Kleber FX. Smoking and hyperlipidemia are important risk factors for coronary artery spasm. Chin Med J (Engl) 2003; 116: 510-513.

9 Sueda S, Kohno H, Fukuda H, Ochi N, Kawada H, Hayashi $\mathrm{Y}$ et al. Clinical impact of selective spasm provocation tests: comparisons between acetylcholine and ergonovine in 1508 examinations. Coron Artery Dis 2004; 15: 491-497.

10 Kim JW, Park CG, Suh SY, Choi CU, Kim EJ, Rha SW et al. Comparison of frequency of coronary spasm in korean patients with versus without myocardial bridging. Am J Cardiol 2007; 100: 1083-1086.

$11 \mathrm{Kim} J W$, Seo HS, Na JO, Suh SY, Choi CU, Kim EJ et al. Myocardial bridging is related to endothelial dysfunction but not to plaque as assessed by intracoronary ultrasound. Heart 2008; 94: 765-769.

12 Chobanian AV, Bakris GL, Black HR, Cushman WC, Green LA, Izzo Jr JL et al. Seventh report of the Joint National Committee on Prevention, Detection, Evaluation, and Treatment of High Blood Pressure. Hypertension 2003; 42: 1206-1252.

13 Yasue H, Mizuno Y, Harada E, Itoh T, Nakagawa H, Nakayama $\mathrm{M}$ et al. Effects of a 3-hydroxy-3-methylglutaryl coenzyme A reductase inhibitor, fluvastatin, on coronary spasm after withdrawal of calcium-channel blockers. J Am Coll Cardiol 2008; 51: 1742-1748.

14 Turnbull F, Neal B, Algert C, Chalmers J, Chapman N, Cutler $\mathrm{J}$ et al. Effects of different blood pressure-lowering regimens on major cardiovascular events in individuals with and without diabetes mellitus: results of prospectively designed overviews of randomized trials. Arch Intern Med 2005; 165: 1410-1419.

15 Mancia G, Messerli F, Bakris G, Zhou Q, Champion A, Pepine CJ. Blood pressure control and improved cardiovascular outcomes in the International Verapamil SR-Trandolapril Study. Hypertension 2007; 50: 299-305.

16 Newman CM, Maseri A, Hackett DR, el-Tamimi HM, Davies GJ. Response of angiographically normal and atherosclerotic left anterior descending coronary arteries to acetylcholine. Am J Cardiol 1990; 66: 1070-1076.

17 Furchgott RF, Zawadzki JV. The obligatory role of endothelial cells in the relaxation of arterial smooth muscle by acetylcholine. Nature 1980; 288: 373-376.

18 Yasue H, Horio Y, Nakamura N, Fujii H, Imoto N, Sonoda $\mathrm{R}$ et al. Induction of coronary artery spasm by acetylcholine in patients with variant angina: possible role of the parasympathetic nervous system in the pathogenesis of coronary artery spasm. Circulation 1986; 74: 955-963.

19 Houghton JL, Davison CA, Kuhner PA, Torossov MT, Strogatz DS, Carr AA. Heterogeneous vasomotor responses of coronary conduit and resistance vessels in hypertension. J Am Coll Cardiol 1998; 31: 374-382.

20 Houghton JL, Strogatz DS, Torosoff MT, Smith VE, Fein SA, Kuhner PA et al. African Americans with LVH demonstrate depressed sensitivity of the coronary microcirculation to stimulated relaxation. Hypertension 2003; 42: 269-276.

21 Kido S, Ishii Y, Hasebe N, Ido A, Kawashima E, Ogawa $\mathrm{Y}$ et al. Significance of coronary risk factors and coronary arteriosclerosis for coronary vasospasm. J Cardiol 1998; 31: 135-143. 
22 Sugiishi M, Takatsu F. Cigarette smoking is a major risk factor for coronary spasm. Circulation 1993; 87: 76-79.

23 Barac A, Campia U, Panza JA. Methods for evaluating endothelial function in humans. Hypertension 2007; 49: 748-760.

24 Treasure CB, Klein JL, Vita JA, Manoukian SV, Renwick GH, Selwyn AP et al. Hypertension and left ventricular hypertrophy are associated with impaired endothelium-mediated relaxation in human coronary (c) This work is licensed under the Creative SOMEREGHSISRESEVIED Commons Attribution-NonCommercial-Share Alike 3.0 Licence. To view a copy of this licence, visit http://creativecommons.org/licenses/by-nc-sa/3.0/ 